International Journal
of
UNIVERSITY OF MURCIA

\title{
An attempt to elaborate a construct to measure the degree of explicitness and implicitness in ELT materials ${ }^{1}$
}

\author{
RAQUEL CRIADO SÁNCHEZ* \\ AQUILINO SÁNCHEZ PÉREZ \\ PASCUAL CANTOS GÓMEZ \\ LACELL Research Group \\ University of Murcia
}

Received: 5 July 2010 / Accepted: 30 September 2010

\begin{abstract}
The concepts of explicit and implicit (knowledge) are at the core of SLA studies. We take explicit as conscious and declarative (knowledge); implicit as unconscious, automatic and procedural (knowledge) (DeKeyser, 2003; R. Ellis, 2005a, 2005b, 2009; Hulstjin, 2005; Robinson, 1996; Schmidt, 1990, 1994). The importance of those concepts and components, we believe, must also be acknowledged in language teaching, and consequently in language teaching materials. However, explicitness and implicitness are rather complex constructs; such complexity allows for multiple nuances and perspectives in their analysis, and this fact poses a real challenge for their identification in the learning and teaching process and materials. We focus here on ELT materials and aim at the building of a reliable construct which may help in the identification of their potential for promoting implicit and explicit components. We first determined the features to identify the construct for implicitness and explicitness; next, we validated it and then we applied it to the analysis of the activities included in three sample units of three textbooks. The results were computed along a continuum ranging from 0 to 10 in each activity. The systematization and computation of results will hopefully offer a reliable figure regarding the identification of the degree of explicitness and/or implicitness in the materials analysed.
\end{abstract}

\section{KEYWORDS:}

Explicit/implicit knowledge, declarative/procedural knowledge, SLA, ELT materials.

\section{RESUMEN}

Los conceptos de (conocimiento) explícito e implícito constituyen uno de los puntos centrales en los estudios sobre la adquisición de lenguas extranjeras. Por explícito se entiende (conocimiento) consciente o declarativo; por implícito, (conocimiento) no consciente, automático y procedimentalizado (DeKeyser, 2003; R. Ellis, 2005a, 2005b, 2009; Hulstjin, 2005; Robinson, 1996; Schmidt, 1990, 1994). La importancia de ambos conceptos debe trasladarse también al campo de la enseñanza de idiomas y por lo tanto a los materiales docentes. Sin embargo, lo explícito e implícito son constructos complejos, y esta complejidad permite muchos matices y perspectivas en su análisis. Este hecho implica que su identificación en los materiales docentes y discentes constituya un verdadero reto. Este trabajo se centra en materiales para la enseñanza del inglés como lengua extranjera. Se pretende elaborar un constructo fiable que pueda ayudar a identificar el componente explícito e implícito que dichos materiales promueven. A tal fin, se determinaron primero los rasgos definitorios del constructo implícito y explícito, y se procedió a su validación. Posteriormente se analizaron con él las actividades de tres unidades completas en tres manuales diferentes de inglés como lengua extranjera. Los resultados se computan dentro de un continuo entre 0 y 10 para cada actividad. La sistematización y cómputo de los resultados confiamos que nos ofrezcan un índice fiable respecto al potencial de explicitud e implicitud que conllevan los materiales analizados.

PALABRAS CLAVE:

Conocimiento explícito/implícito, conocimiento declarativo / procedimental, adquisición de segundas lenguas, materiales para la enseñanza del inglés como lengua extranjera.

\footnotetext{
*Address for correspondence: Raquel Criado Sánchez, Aquilino Sánchez Pérez and Pascual Cantos Gómez. Departamento de Filología Inglesa, Facultad de Letras, Campus de La Merced, 30071. Murcia, Spain. E-mails: rcriado@um.es, asanchez@um.es, pcantos@um.es
} 


\section{INTRODUCTION}

SLA research does not necessarily have to have a direct bearing on teaching, but it seems reasonable to expect that SLA research and its principled conclusions could and perhaps should be taken as a sound reference for defining and deciding on methods and techniques in Foreign Language Teaching (FLT). In this sense, we fully agree with Dornyei (2009) when he vindicates the practical and useful side of SLA studies. It seems natural to associate research on learning with research and practice in teaching. After all, the mechanisms governing language learning should not be dissociated from the techniques applied in language teaching. In other words, teaching must be designed and planned in compliance with the processes and paths that condition and channel language learning, be it of a first, second, or third language.

Following the premise above, the aim in this paper is the identification of the potential of implicit and explicit components in English Language Teaching (ELT) materials. We will therefore look at the materials used by students in their learning path, but we do not aim to analyse in any way the outcome of the teaching process (that is, the actual learning achieved). In order to reach our goal, we will first explain with some detail what is meant by 'explicit' or 'implicit' knowledge and/or language acquisition (a variety of knowledge acquisition). On the basis of this rationale, we will then attempt to define the constructs of "explicit" and "implicit". This is a necessary condition in order to identify and measure the explicit and implicit components in language teaching materials.

Language teaching materials will refer to ELT. In this respect, we will take activities (as they appear in ELT textbooks) as the minimal teaching units on which the analysis will be based. Activities are in fact the units in which teaching becomes operative in the classroom. Further to that, activities will be analysed from the perspective of their goals and the strategies designed to achieve such goals. In our view, goals and strategies are the main constituents of activities.

Once the construct for explicitness and implicitness was defined (subsections IV.1 and IV.2), we applied it in the analysis of representative samples of the activities from three different ELT textbooks (see subsection IV.3). The results of such an analysis will be given in coefficients of explicitness and implicitness for each activity on a scale within the range $0-10$.

\section{THE NATURE OF EXPLICITNESS AND IMPLICITNESS}

The concepts of explicit and implicit (knowledge) are at the core of some of the most important issues in SLA. Explicit is typically associated with conscious and declarative 
knowledge; implicit with unconscious, automatic and procedural knowledge (DeKeyser, 2003; R. Ellis, 2005a, 2005b; Hulstjin, 2005; Robinson, 1996; Schmidt, 1990, 1994). Krashen’s dichotomy (Krashen 1981), learning vs. acquisition, can also be related to explicit and implicit respectively, since learning is associated with consciousness and requires explicitness while acquisition is unconscious and implies implicitness.

The terms explicit/implicit have an ample coverage (Dörnyei, 2009). They are applied to different concepts and fields: to knowledge itself (implicit/explicit knowledge), to learning (explicit/implicit learning), and to memory or information storing (explicit/implicit memory). The meaning of explicit/implicit maintains the core features in all these uses, particularly those concerning the role of consciousness, but its application to knowledge, learning or memory results in important differences regarding the end-product.

When applied to knowledge, explicit stands for a conscious kind of information, which we may therefore control and be aware of. Explicit as applied to learning refers to a specific way of acquiring this type of knowledge, through the activation of consciousness and intentionality. Explicit as applied to memory refers to a particular way of storing information in our memory, that is, keeping it on-line, consciously controlled and managed. The term implicit runs parallel to explicit in each one of the instances mentioned above, but in the opposite direction. Implicit knowledge is the kind of information we do not consciously control; implicit learning is the type of learning which takes place without intentionality, automatically and responding to context-dependent stimuli, which are responsible for triggering unconscious processes; implicit memory is the kind of memory that stores information outside the reach of our conscious control.

We will use here the term explicit as implying consciousness, awareness and/or reasoning, while implicit excludes consciousness, or conscious control of the processes performed. Explicit or declarative knowledge is the kind of knowledge we have access to, knowledge we can declare, we are aware and conscious of. This type of knowledge can be verbalized and consciously controlled. Implicit or procedural knowledge, on the other hand, is the kind of knowledge we are not conscious about. This kind of knowledge does not require our conscious collaboration as it is automatic and proceduralized; once triggered, it proceeds automatically until it comes to a final goal (Anderson, 2005; Hulstjin, 2005; Schmidt, 1993a, 1993b). In other words, we are aware of the results, but we are not aware of how and why those results are achieved (Paradis, 2009). Implicit knowledge and learning is outside the range of our conscious control, so much so that we may be willing to acquire and proceduralize specific knowledge and we may end up acquiring pieces of knowledge we did not intend to acquire, while we may fail in the acquisition of goals we consciously intended to achieve (Schmidt, 1990). 
A current hot debate in SLA concerns the specific role of explicit/declarative knowledge in language acquisition, which is known as the interface issue, with three positions: noninterface, strong and weak. Firstly, Krashen (1982) is the most representative author of the non-interface position between explicit and implicit knowledge, since the former cannot be transformed into the latter; in teaching terms, there is no interface given that what is learned explicitly is not usable in real, spontaneous communication. This position is seemingly underpinned by research that suggests that explicit and implicit memories are neurologically separate (Paradis, 1994, 2009).

Secondly, some scholars, such as DeKeyser (1998, 2003, 2007a, 2007b), advocate a strong interface position, by which declarative knowledge is a springboard towards implicit or proceduralized knowledge. This position in SLA owes very much to Anderson's ACT-R model of skill learning (Anderson, 1982; Anderson et al., 2004). Anderson's model has been particularly influential in SLA and Foreign Language Teaching studies (Criado-Sánchez, 2008, 2010; DeKeyser, 1998, 2007a, 2007b; Johnson, 1994, 1996, 2008; O’Malley, Chamot \& Walker et al., 1987).

Thirdly, N. C. Ellis and R. Ellis argue for a weak interface position. N. C. Ellis (2005, 2006, 2007) favours a largely implicit view on language acquisition, “associative” and "rational”, where explicit learning can help, among other things, noticing for intake. R. Ellis (1994, 2006, 2008) concedes that explicit knowledge can lead to implicit knowledge as long as the grammatical features in question are developmental (cf. Pienemann, 1989). Besides, the weak interface position advocates the role of consciousness and noticing in language learning (Schmidt, 1990, 1994; Sharwood-Smith, 1991, 1993). This has given way to a number of related pedagogical techniques: input enhancement or consciousness-raising, input enrichment or input flooding, which in combination with explicit instruction leads to noticing instruction, etc. Enriched input is "input where a specific L2 feature occurs with high frequency” (Reinders \& R. Ellis, 2009: 282), which in the context of a meaning-focused activity results in incidental learning, whilst enhanced input is "input where the target feature has been emphasized in some way -glossing, bolding or underlining” (Reinders \& R. Ellis, 2009: 283). As R. Ellis (2005b: 215) states, “explicit knowledge of a grammatical structure makes it more likely learners will attend to the structure in the input and carry out the cognitive comparison between what they observe in the input and their own output”. For an excellent review of these teaching techniques, see Mackey and Abbhul, 2005; Sanz \& Morgan Short, 2005 and Reinders \& R. Ellis, 2009.

The debate on the interface issue is still undecided, but the experience of adult language learning cannot but support the view that conscious learning is an important element in the acquisition of knowledge, even if the details of how this takes place are still blurred. 
Last, but not least in importance due to the Foreign Language Teaching framework of this article, the terms explicit and implicit can and should also be applied to teaching. For that purpose we will draw on DeKeyser's (2003) four categories of learning resulting from the combination of the inductive/deductive and implicit/explicit dimensions. These four categories of learning entail different types of teaching:

1) Explicit deductive learning, which is achieved via traditional rule teaching.

2) Explicit inductive learning, which is attained through rule discovery or discoverylearning. This involves consciousness-raising, input enhancement and its derived noticing instruction (see above).

3) Implicit deductive learning, which is the least obvious and can be illustrated by the concept of parameter setting in Universal Grammar;

4) Implicit inductive learning, which corresponds to natural L1 learning.

Current ELT and FLT materials offer instances of 1) and 2) and virtually neglect 3) whilst offering pedagogical adaptations of 4 ), as will be seen in section IV.

\section{THE COGNITIVE LEARNING PATH AND TEACHING PRACTICES}

\section{III.1 Learning and teaching}

We shall focus our attention in this section on the learning process triggered by teaching materials, insofar as those external factors or elements affect the learning path of the individual. Those materials (and the activities through which they are implemented in the classroom) are selected and presented according to methodological and pedagogical criteria defined by the textbook author and the teacher; they are also necessarily sequenced in a particular way, which may or may not adjust to the cognitive sequence inherent to the process governing knowledge acquisition by human beings, and they aim at the achievement of specific goals regarding the kind of knowledge to be acquired. Moreover, the activities deployed in language teaching may or may not be the most efficient ones in facilitating and promoting the acquisition of specific types of knowledge, which, as mentioned above, are also biologically conditioned. In other words, we will consider instructed language teaching as an outside and 'foreign' drive that may - or may not - run parallel to the individual cognitive process and may - or may not - help its activation and consolidation.

Instruction implies by definition an attempt at intervening and somehow interfering in language learning. Such an intervention is not univocal. It may be direct or indirect (R. Ellis, 
2009; see Criado Sánchez, 2008 and 2010, for direct and indirect types of language presentation via aural and written texts), very much in parallel with the explicit/implicit dichotomy. The terms fit our purpose here, since what we shall do is precisely to analyze the teaching materials from the perspective of explicit and implicit teaching. Still, it is not clear that 'indirect' intervention should always lead to implicit learning. Any kind of instruction tends to be pedagogically conditioned, and the learner does not necessarily proceduralize the input that teaching materials include or the goals they aim at. This is linked to the "readinessto-learn” principle, which is used by some researchers to argue that learners do not necessarily learn everything they are taught (Tomlinson, 1998; D. Willis \& J. Willis, 2007).

However, it is also admitted that 'indirect' intervention may promote implicit learning, especially if the materials are authentic and provide opportunities for using the language in relevant communicative situations. In any event, we should bear in mind the restrictions inherent to instruction in general and especially the limited scope of the materials students work with in the classroom.

'Direct' intervention implies the explicit teaching of the rules and vocabulary of the language. It can entail either a deductive or an inductive mode. In the former, students are taught the rules prior to any other work with such rules; in the latter, the students discover by themselves the rules or meanings present in isolated samples of language or in an aural or written text. It should be taken into account that such inductive "discovery" presents two variants: students are either explicitly asked to find out the rules and meanings or they are supposed to induce them through repetition, as was the case in the Structural Methods with the repetition of structures in aural dialogues and drills. As can be seen in this last case, the teaching technique is explicit although the learning might take place implicitly, since students might be conscious or not of the targeted linguistic items. In the three cases (deductive plus the two inductive variants) texts might be used and should be previously pedagogically adapted in different ways to include the targeted linguistic features. Such an adaptation can draw on enriched input or enhanced input (if using written texts) that is intended to be noticed by the students, a technique found frequently in Communicative Language Teaching (CLT) materials. Indirect or implicit intervention does not purposefully attract the learners' conscious attention to word meanings or rules and thus does not use any specific pedagogical tool targeted at such elements; it might well be the case that activities and teaching procedures are aimed at the practice of skills per se from a holistic perspective.

Ideally, there should not be a divorce between the biologically-conditioned cognitive path in knowledge acquisition (restricted and conditioned by built-in neural processes) and the way we are supposed to learn in artificial and classroom settings, conditioned by the kind of teaching activities and the method applied. It can reasonably be predicted that a mismatch 
between the learning mechanisms our mind is submitted to by nature and the characteristics of the pedagogical practices directed at learning will not be positive for the learning process itself. That is, teaching practice should not be dissociated from the cognitive learning path set out by consolidated learning routines and particularly by our neural network.

\section{III.2 Adult instructed acquisition}

It is important to state that the analysis we conduct here (i) is based on teaching materials for adults, and (ii) is restricted to instructional settings. We assume that the adult cognitive path within an instructed learning environment is specific or, at least partially different from children's cognitive path in natural settings. We know, for example, that explicitness plays an important role in teaching adults, while in children it is or may be absent. At the same time, the acquisition of implicit knowledge plays an important role in learning, in both adults and children, even though it is difficult to define such a role precisely.

Instructed acquisition and learning may be considered from two perspectives, (i) external, that is, from the perspective of teaching (information delivered and meant to be acquired), and (ii) internal, that is, from the perspective of the learner (information effectively acquired). There is not necessarily any coincidence between both perspectives and modes of learning. As stated above, it is well known that students quite often learn what has not been taught, while sometimes they actually learn what they have been instructed to learn (Long and Robinson, 1998; Rod Ellis, 2009; Schmidt, 1990). This dichotomy (learning vs. teaching) helps understand why explicit or implicit teaching does not always lead to explicit or implicit knowledge acquisition. On the other hand, this potential mismatch should not lose sight of the fact that quite often explicit teaching does result in explicit learning, and that there is a reasonable probability that implicit teaching will result in implicit learning. In terms of language teaching materials, it is also reasonable to assume such learning expectations here.

Accordingly, matching the way of learning with the way of teaching will first require that both processes agree in that they are guided by the same principles and follow similar paths and sequencing of actions. If we focus our analysis on the role of explicit and implicit teaching and their probable influence on explicit and implicit learning, it is meaningful to analyze the degree of potential explicitness and implicitness in the teaching materials. We do not intend, however, to take a stand for explicit or implicit teaching. We just aim to gather data extracted from real teaching materials regarding the amount of explicit or implicit teaching they contain and promote through the activities they offer. 


\section{THE TEACHING MATERIALS: THE IMPLICIT AND EXPLICIT CONSTRUCT}

\section{IV.1. The content of the construct}

The most important decision in defining the explicit and implicit constructs is the selection of their constituent features. The elements identified must be enunciated clearly and sharply, bearing in mind that they must be easy to detect in real textbook activities. The difficulty in defining the explicit and implicit load in teaching materials derives from the complexity of the input provided by the activities themselves.

Explicitness is obvious in the activities typical of the Grammar-Translation method, and in many classrooms as well, when teachers intervene with direct explanations on the structure of the language and require from students full explicit attention to form. In a similar way, implicitness is obvious in most natural methods (the Direct Method, for example), where focus on form is overtly forbidden. But activities in modern textbooks abound in variety and nuances as to the way they are presented. The Audiolingual Method, for example, provided pedagogically arranged materials in the sense that the structures were carefully selected and arranged in dialogues and drills, while on the other hand it asked the teacher to avoid any explicit information on the language taught (Richards \& Rodgers, 2001; Sánchez, 2009).

In most textbooks available nowadays, many activities are apparently presented with non-explicit information on the linguistic system, but the authors take advantage of various 'indirect' devices and strategies to draw the attention of the students to some specific forms or underlying rules and patterns; some words are highlighted in bold or in different colour (which are instances of the input enhancement technique previously defined); some structures are intensively repeated (even in context), which accounts for input enhancement; gaps in authentic texts must be filled in with words of a particular nature and with a particular function in the language, etc. In these circumstances, the analysis and the identification of explicitness or implicitness is not as transparent as expected. The amount of technical terms found in the literature on this topic (the recently mentioned input enhancement, enriched input, plus incidental learning, intentional learning, noticing, intake and the like) reveals the complexity of the issue (Hulstijn, 2003; Reinders \& R. Ellis, 2009; Schmidt, 1990, 1994; Sharwood-Smith, 1991, 1993, among others).

With such complexity and caveats in mind, we have selected a list of features which, in our view, cover the basic characteristics of explicit teaching; their opposites will then cater for implicit teaching: 
1. Looks for awareness of formal aspects of the language

2. Focuses on metalinguistic information of the language

3. Promotes declarative knowledge on the language

4. Focuses primarily on form

5. Favours linguistic accuracy

6. Uses non-authentic materials

7. Requires the use of L1

8. Aims at controlled use of the language

9. Entails non-meaningful mechanical repetition

Many authors in SLA (Leow, 1997, 2001; Rosa \& O’Neill, 1999; Schmidt, 1990, 2001, etc.) agree on the need for awareness as a requirement for noticing, which, in turn, "is the necessary and sufficient condition for the conversion of input into intake” (Schmidt, 1993: 209). Together with awareness, the focus on metalinguistic information, on declarative knowledge and on form (features 1, 2, 3 and 4 respectively) are related to activities centred on the formal system of the language. This is the case of exercises based on grammar and quite often on vocabulary or pronunciation. In feature 2, the goal and strategy coincide (this explains why the cell for the strategy has been excluded, as shown in Table 1, below). This feature is a sub-specification of feature 4, as focus on form might be undertaken from an explicit deductive or inductive mode; the former always includes metalinguistic information, whereas the latter does so in discovery learning but not so much in methods which reject the inclusion of explicit information on the rules and meanings of the language, such as the Structural Methods (see section III.1.).

Feature 5 also caters for a feature closely linked to formal aspects: accuracy, since accuracy demands attention to form in the language learned or used. Feature 6 takes into account the kind of materials underlying the activity. It is assumed here that authentic materials favour implicit learning because they are a more direct reflection of natural linguistic usage, while non-authentic materials are pedagogically arranged and are therefore somehow conditioned by specific (most often formal) aspects of the language that must be (deductively or inductively) stressed while teaching/learning. The use of L1 (feature 7) while learning a second language entails awareness of the linguistic system and it applies to the strategy alone. Therefore, it favors explicit knowledge. Both features 6 and 7 are strategies rather than goals: this is why the cells for goals are also excluded in the computation. Whenever the activity asks for controlled linguistic output, explicit knowledge of the language is favored (feature 8). Feature 9 relates to the presence or absence of mechanical and non-meaningful repetition. This is typically the case of drills, pattern practice and activities in general based on the repetition of the same formal elements in non-contextualized 
communicative settings. They do not favor the building of implicit knowledge; insofar as they have been pedagogically planned and arranged attending to the acquisition of specific linguistic forms, they will rather contribute to explicit knowledge, even if inductively promoted.

Finally, it is also important to highlight that we intend to measure the potential of the activities regarding the promotion of explicit or implicit learning. However, we do not attempt to assume that explicit and implicit teaching as materialised in the activities will actually result in the students' explicit or implicit learning. The study and measurement of what is taught or is meant to be taught versus what is really learnt or acquired would constitute a different endeavour.

\section{IV.2. Shaping the construct}

Textbooks are typically organized in units or lessons, which in their turn contain activities or exercises. The teaching action is transmitted to students through activities. Activities are defined by a specific structure, and their potential for promoting explicit or implicit knowledge will depend on the nature of their constituent elements. The teaching actions we call "activities" develop around two axes: (i) the goal they aim at and (ii) the strategies planned to reach such a goal. The goal is the objective aimed at by the activity, and the strategies are the means to reach such a goal. For instance, the goal of a reading activity might be getting the gist. This might be attained through different strategies: matching paragraphs with pictures depicting the main scenes, selecting the best summary out of a list, asking the students to provide a summary themselves, etc.

If we identify and analyse the goals and the strategies of each activity from the point of view of explicitness and implicitness, we will be able to discover whether those ingredients are present or not and to what extent. The explicitness and implicitness of the construct will be revealed by the strategies underlying each activity and by the output they are expected to generate, i.e., the expected outcome/goal.

It should be borne in mind that the explicit and implicit elements are not always neatly shaped and delimited. Instead, both components appear often as fuzzy elements in which features from one component seem to be present or interact with features from the other component. This fact leads us to conclude that the measurement scale for each activity cannot be designed with absolute values, in terms of YES or NO regarding explicitness or implicitness. On the contrary, the scale should be inclusive, i.e., open to the presence and interaction of both explicit and implicit features. The use of a scale in which explicitness and implicitness may appear together seems to be closer to activities in which emphasis on formal 
elements does not exclude attention to meaning, or vice versa. Such a scale may be visualized as a continuum with two end-points, a maximum (10) (+explicit/-implicit) and a minimum (0) (-explicit/+implicit). Figure 1 shows the gradation of the continuum regarding both endpoints:

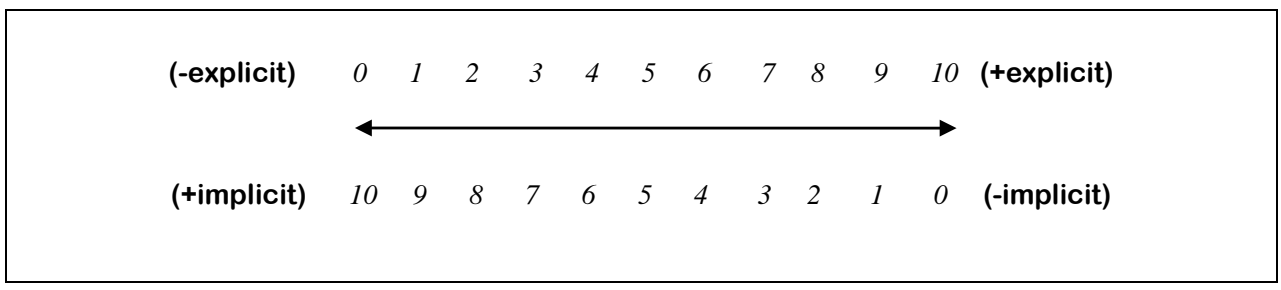

Figure 1. The explicit and implicit teaching continuum

The sum of the values of the explicit/implicit components will always be 10 at any point in the continuum. This fact assumes that when explicitness is high, implicitness is low, and vice versa; when explicitness reaches the maximum, implicitness is non-existent, and vice versa; In other words, when an activity requires full attention to form, attention to meaning is zero, and viceversa. If the emphasis on a specific feature promoting, say, explicitness, is somewhere between the minimum and the maximum, this very fact conditions the intensity of its opposite, implicitness.

Full explicitness and implicitness are therefore at opposite poles on the same scale and interact with each other depending on the location of each one of them on the continuum; the location of one of them conditions the location of the other (as shown in Figure 1). Put another way, the degree of explicitness and implicitness are correlated to each other: if the maximum in the scale is 10 , when the degree of explicitness is, say, +5 , the degree of implicitness will also be necessarily +5 ; if the degree of implicitness is +10 , the degree of explicitness will be necessarily 0 , since the whole spectrum of the scale is taken up by the implicit construct. This applies to every one of the activities analysed as regards goals and strategies, as shall be seen below.

\section{IV.3. Applying the construct}

The original thing about the construct described above is that it is not only a theoretical construct; it may also derive into a practical instrument to detect the degree of explicitness and implicitness of teaching materials. This is possible due to the fact that the actual construct consists of a list of the features for explicit and implicit teaching, which can be used as a checklist when examining activities. 
Table 1 shows the adaptation of the construct into a practical tool for measuring. This table has been designed to be implemented in Excel in such a way as to facilitate the computation of data.

\begin{tabular}{|ll|l|l|l|l|}
\hline \multirow{2}{*}{ Activity } & \multicolumn{3}{l|}{ Goal } & \multicolumn{2}{l|}{ Strategy } \\
\cline { 3 - 6 } & Explicit & Implicit & Explicit & Implicit \\
\cline { 3 - 6 } & Yes & No & Yes & No \\
\hline 1. $\quad$ Looks for awareness of formal aspects of the language & & & & \\
\hline 2. $\quad$ Focuses on metalinguistic information of the language & & & & \\
\hline 3. $\quad$ Promotes declarative knowledge on the language & & & & \\
\hline 4. $\quad$ Focuses primarily on form & & & & \\
\hline 5. $\quad$ Favours linguistic accuracy & & & & \\
\hline 6. $\quad$ Uses non-authentic materials & & & & \\
\hline 7. $\quad$ Requires the use of L1 & & & & \\
\hline 8. $\quad$ Aims at controlled use of the language & & & & \\
\hline 9. $\quad$ Entails non-meaningful mechanical repetition & & & & \\
\hline
\end{tabular}

Table 1. The practical construct for the analysis and measurement of implicitness/explicitness

The weight of explicitness or implicitness results from the presence or absence (YES or NO) of each one of the features in every single activity. The column on the left contains the nine features listed in subsection IV.1. The columns on the right allow for a positive or negative mark (YES/NO, YES for explicitness, NO for implicitness), both from the point of view of the Goal and the Strategy.

The analysis proceeds in the following way: in each activity, we mark the cell Yes or No for the explicit and implicit modes as appropriate in the column of Goal and Strategy; if the feature is present in the explicit mode, for instance, 1 is marked in the pertinent cell of the explicit column; otherwise, nothing is typed there. Table 2 on page 115 offers the sample analysis of an activity taken from New English File Elementary Student's Book (published in 2004 by Oxford University Press):

The same procedure is followed in the fifteen cells. The computer counts the marks in each column, computes the total of explicitness or implicitness to 10 in each column and finally calculates the total of explicitness and implicitness to 10 again in the goal and strategy columns from the rows "Explicit teaching" and "Implicit teaching”. This computing appears at the end of each activity (in the column 'Total') as in Table 2. 


\begin{tabular}{|l|c|c|c|c|}
\hline Activity no. 14 & \multicolumn{2}{|c|}{ Goal } & \multicolumn{2}{c|}{ Strategy } \\
\cline { 2 - 4 } $\begin{array}{l}\text { 5.b. Listen to a TV cooking programme. What nine things } \\
\text { does Colin use to make spaghetti Bolognese? }\end{array}$ & Explicit & Implicit & \multicolumn{1}{c|}{ Explicit } & Implicit \\
\cline { 2 - 4 } & Yes & No & Yes & No \\
\hline 1. Looks for awareness of formal aspects of the language & 1 & & & 1 \\
\hline 2. Focuses on metalinguistic information of the language & 1 & & & \\
\hline 3. Promotes declarative knowledge on the language & 1 & & & 1 \\
\hline 4. Focuses primarily on form & 1 & & & 1 \\
\hline 5. Favours linguistic accuracy & 1 & & & 1 \\
\hline 6. Uses non-authentic materials & & & & 1 \\
\hline 7. Requires the use of L1 & & & & 1 \\
\hline 8. Aims at controlled use of the language & 1 & & 1 & \\
\hline 9. Entails non-meaningful mechanical repetition & & 1 & & 1 \\
\hline & & & & \\
\hline & Goals & Strategies & Total & \\
\hline Explicit teaching & 8.57 & 1.25 & 4.91 & \\
\hline Implicit teaching & 1.43 & 8.75 & 5.09 & \\
\hline
\end{tabular}

Table 2. Sample analysis of an activity

The analysis carried out is illustrated with more detail in the following sample activities taken from the materials used (see section $\mathrm{V}$ for their references).

i) Activity 1. Listen to a TV cooking programme. What nine things does Colin use to make spaghetti Bolognese?

This listening activity is centered on discrete items of vocabulary (names of cooking ingredients). Accordingly, despite the fact that the lexical elements are contextualized in an aural text, the activity belongs to the explicit mode of teaching in the column of goals -all the features except for 9 are met. The column of strategies is, however, predominantly implicit, thanks precisely to the above-mentioned contextualization in an aural text, which somehow "disguises" or "softens" a sheer focus on form without any contextualization at all. As a result, the continuum results in 4.91 for explicitness and 5.09 for implicitness.

ii) Activity 2: Read the introduction and the questionnaire.

This reading activity aims at understanding a text without any other type of task required on the learners' part. Thus, it promotes implicit learning through language use in all the nine features, since focus on form and formal accuracy are not promoted. This is a prototypical example of enhanced input. The continuum will show this fact with the highest mark for implicitness (10) and the minimum for explicitness, (0), for both goals and strategies.

iii) Activity 3: Underline the examples of (be) going to in the dialogue.

1. What form is the verb going to?

2. Do we use going to to talk about the past, the present or the future? 
This activity seems to bear a high load of explicit teaching (features 1, 2, 3, 4, 5, 6 and 8 are met, for both goals and strategies). But the explicit character is partially downgraded because features 7 and 9 are not met (either in goals and strategies) and thus they promote implicitness. The exercise does not require the use of the L1 (feature 7), and given that the dialogue is communicatively contextualized (though not authentic), the exercise does not entail non-meaningful mechanical repetition (feature 9). The computing in the continuum will result in 8.04 for explicitness and 1.96 for implicitness. Overall, this activity seems to promote mainly explicit learning but it contains elements associated with 'enriched input', which, together with explicit instruction to the learners on forms results in 'noticing instruction’ (Reinders \& R. Ellis, 2009).

iv) Activity 64: Look at the photo. Which of the following can you see? (out of a total of 16 vocabulary elements presented: bananas, bread...).

This activity is centered on vocabulary teaching. Students are invited to pay attention to each one of the words in the table and check whether they are in the photo. In doing so, their attention is drawn to the form of the words; at the same time though, they must pay attention to their meaning and they can only succeed in the identification task if they manage to match the form of each element with the corresponding picture in the photo. The continuum results therefore in a total of 7.1 for explicitness (features 1, 2, 3, 4, 5, 8 are met, for both goals and strategies) and 2.59 for implicitness (features 6, 7, 9 are met, also for both goals and strategies).

\section{IV.4. The validation of the construct}

To validate the construct, three judges (university lecturers and experts in the area) were selected and asked to rate independently 23 randomly chosen activities, previously extracted from the textbooks analyzed here. Next the ratings of each of the judges were examined by means of Pearson Correlation Test, in order to determine if the judges assigned similar rates to the 23 randomly chosen activities or not. The correlation test revealed highly significant similarities among the judges (judge 1 vs. judge 2 : $\rho=0.8847, p<0.05$; judge 1 vs. judge 3 : $\rho=0.8401, \mathrm{p}<0.05$; judge 2 vs. judge 3: $\rho=0.8489, \mathrm{p}<0.05$ ). In addition, a Friedman Test was applied, in order to determine whether the potential minor differences encountered among the judges' ratings could result into statistically significant discrepancies. Again, the divergence among judges resulted into non-significant $\left(\chi^{2}=0.933, \mathrm{df}=2, \mathrm{p}=0.627\right)$. Though this validity testing is not completely conclusive, the data are very positive and the construct seems highly valid and also like to be reliable. 


\section{THE UNITS ANALYSED}

The teaching materials analysed here were taken from three ELT textbooks:

- Lebeau, Ian \& Rees, G. (2008). Language Leader Elementary Coursebook and CDROM. Harlow: Pearson/Longman (henceforth referred to as $L L$ );

- Oxenden, C., Latham-Koening, C. \& Seligson, P. (2009). New English File Elementary Student's Book. Oxford: Oxford University Press (henceforth referred to as $N E F)$;

- Redston, C. \& Cunningham, G. (2005). Face2face Elementary. Student's Book. Cambridge: Cambridge University Press (henceforth referred to as F2F).

All the textbooks belong to the elementary level for reasons of homogeneity; besides, we only selected the elementary level as we thought it pertinent to start with this level and to continue expanding the application of our construct to more advanced levels later. As for the textbooks themselves, they were selected because they are very well-known materials in the international ELT commercial market.

We have selected a unit from each one of the textbooks: unit 7 from NEF, Unit 8 from F2F and unit 6 from LL. The selection was made at random.

The units selected are structured in various sections, centering on skills (reading, listening, writing and speaking) and subskills (named as such in opposition to the four skills and which include grammar, vocabulary and pronunciation). They include many activities: between 64 and 82 . The total number of activities is 225. The activities have been carefully analysed following the criteria mentioned in section IV. Due to space restrictions, a sample analysis of each one of the units is given in the Appendix.

\section{ANALYSIS OF DATA}

Our data reveal the leading role of implicitness with an overwhelming majority: the balance in the three textbooks is around. 2/3 for implicitness and 1/3 for explicitness, as can be seen in Graph 1, which shows a global mean of 3.97 for explicitness and 6.03 for implicitness: 


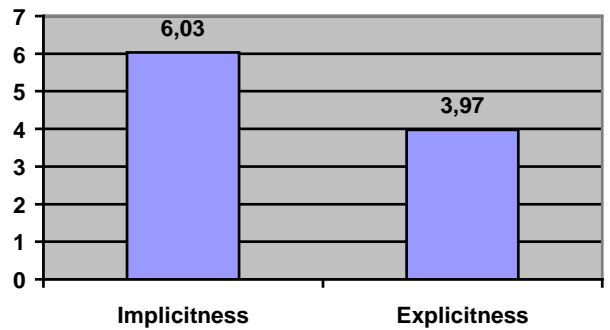

Graph 1. Global mean-weight for implicitness and explicitness in the three textbooks

Regarding the promotion of explicitness and implicitness, the three textbooks are strikingly similar overall (Graph 2). Differences are not relevant, which proves that these textbooks keep a similar profile in the promotion of explicitness and implicitness. That is, if teachers aim at contrasting the weight assigned to implicitness and/or explicitness more sharply, those textbooks are not the right candidates for significant changes in this component.

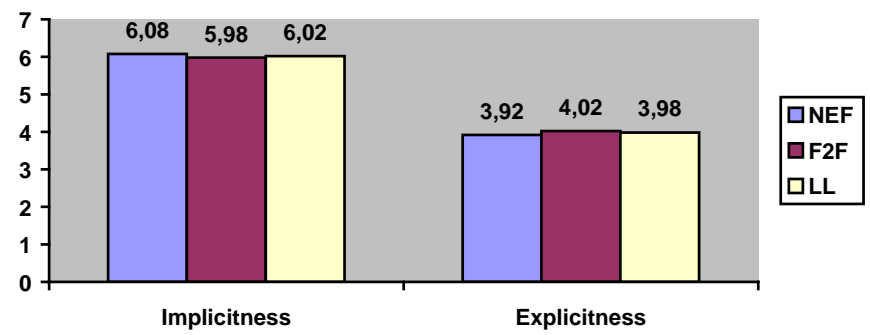

Graph 2. Mean-weight for implicitness and explicitness in each textbook

The emphasis given to implicitness vs. explicitness entails important consequences in relation to the methodological approach or the method that textbooks adjust to. On the one hand, the weight of implicitness proves that teaching materials are in line with some basic tenets in the CLT (Richards \& Rodgers, 2001; Sánchez, 2009). The 'natural way of learning' and the importance of 'meaningful input' seem to take the lead and displace methods with a heavier bias towards form. Focus on meaning and abundant occasions for exposure to linguistic input prevail in the design of the activities. On the other hand, the emphasis on explicitness and grammar and the role of deductive processes, although noticeably lower in weight, are nonetheless important in the three textbooks. This also proves that the role of consciousness in teaching is taken into consideration (even if not always shaped in the “consciousness-raising” technique; see section II). If around $1 / 3$ of the features analysed 
promote explicitness, we can conclude that an important place in the teaching process is covered by teaching focused on form - whether "focus-on-form" or "focus-on-formS", following Long \& Robinson's classical distinction (1998). The CLT, and more specifically the Common European Framework (2001), advocate a communicative perspective in teaching and tend to neglect the role of grammar and deductive activities. The presence of the explicit component reveals, however, that textbooks do not neglect consolidated beliefs in the need for explicit teaching. The result of this global appraisal is that the prevailing underlying method is communicative (CLT), even though elements from other methods emphasizing the formal aspects of language also play an important role.

Nevertheless, conclusions based on the global analysis of the units should be nuanced. Units are typically structured in sections, which usually correspond to the four skills (reading, writing, listening, speaking) and three sub-skills (grammar, vocabulary, pronunciation). This structure constitutes the backbone of each unit in the three textbooks, with only minor variants in one of them (LL). Looking at the same data in detail and from a different perspective, the results shed some light on how explicitness and implicitness are distributed across the textbooks and across skills and subskills. It would be interesting to discover whether the weight of explicitness and implicitness is equally shared by or distributed in the various sections underlying the organization of the units. The number and nature of activities devoted to each one of the skills and subskills may exert a decisive influence on the weight of explicitness or implicitness in the unit. On the one hand, skills are of a more global nature than subskills and tend to favour a more comprehensive teaching action, given that skills themselves involve the mastery and/or practice of grammar, vocabulary and pronunciation for a correct performance. On the other hand, subskills are closer to the formal component of language (as is clearly the case of grammar) and they are also more centred on discrete linguistic elements. In this respect, as Graph 3 shows, each textbook is noticeably different regarding the presence or absence of explicitness or implicitness.

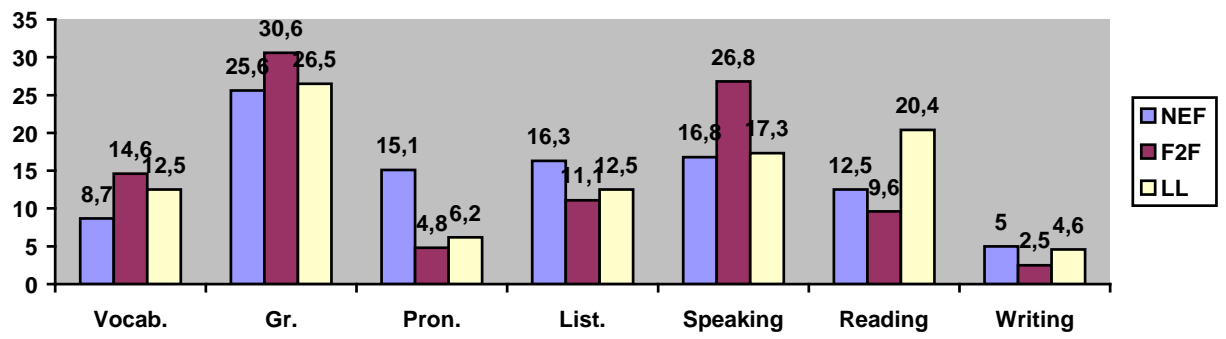

Graph 3. Percentage of activities per skill and sub-skill in each textbook 
Grammar-based activities receive more attention than any other skill or subskill in the three textbooks. F2F grants a leading role to speaking also (26.8\%), if compared to NEF and LL. NEF differs significantly from F2F and LL in the number of activities promoting all the skills and subskills, except in the grammatical component (25.6\%, 30.6\% and 26.5\% in NEF, F2F and LL respectively) and partially in the speaking skill. Reading receives a clear emphasis in LL and Pronunciation is emphasized in NEF (15.1\% as opposed to $4.8 \%$ in F2F and $6.2 \%$ in LL). It can also be appreciated that skills and subskills do not receive homogeneous attention in all the textbooks analysed here, except in grammar, where numbers are closer.

The above-mentioned comprehensive and holistic nature of the four skills will require activities in which language use in communicative contexts is favoured. Setting up true communicative contexts (meant to transmit information and therefore more centred on meaning) will also ask for true communicative teaching activities, that is, activities in which speakers engage in sharing or transmitting meaningful content. This, in its turn, will require focus on meaning rather than form, and consequently implicit learning will be favoured. Explicit teaching (either focus on form or formS) is not excluded in those instances, but it is less likely to happen, since explicitness demands conscious attention to the linguistic forms underlying meaning. Hence, the conscious processing of linguistic information would necessarily lower attention to what is being said (content or meaning) and provoke communicative gaps or breakdowns.

Thus, given that skills per se are holistic and necessarily meaning-centred, it can be affirmed that the prevalence of implicitness in skills is a logical outcome; explicitness tends to stress specific linguistic elements (form) at the expense of meaning, which would be assigned a secondary role. The weight of implicitness vs. explicitness in skills and subskills is shown in Graph 4 and confirms such an analysis:
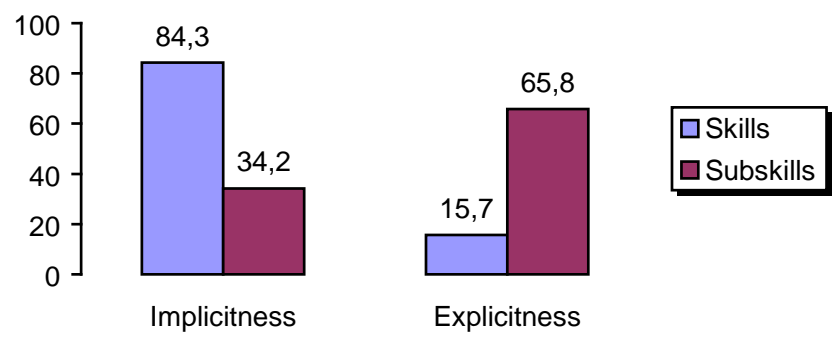

Graph 4. The weight of explicitness and implicitness in skills and sub-skills (in percentages) 
More specifically, three of the skills (listening, speaking, reading) are consistent in this tendency of promoting implicitness over explicitness, while one of them (writing) shows a significantly lower emphasis on implicitness (Graph 5). The association of writing to the formal use of language - that is to say, neat handwriting, correct spelling and punctuation, as well as acceptable grammar and careful selection of vocabulary - may be the reason for this variant.

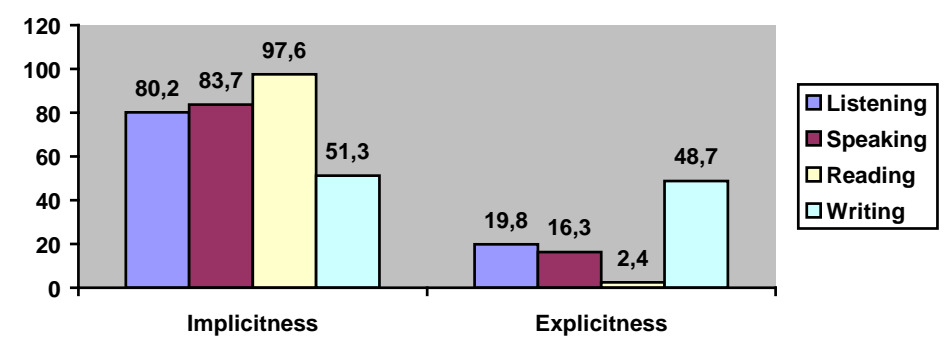

Graph 5. The weight of explicitness and implicitness per skill (in percentages)

Subkills (grammar, vocabulary and pronunciation) are included in the three textbooks in separate sections. The role of grammar in each one of the textbooks, as specified in Graph 3, is well grounded; an average of $27.6 \%$ of the activities belong to the grammar sections. Next in importance is speaking (20.1\%), followed by reading (14.2\%) and listening (13.3\%). Writing receives much less attention (4\%) in all the textbooks analysed. Grammar is and has traditionally been associated with the teaching of the formal component of language, and specifically the rules governing the system. The teaching of grammar tends to be predominantly explicit, following deductive procedures. That was always and systematically the case in the Grammar-translation Method. Within CLT, grammar is also taught inductively (often through enriched or enhanced input). The proportion of explicit and implicit features in the activities within the grammar section reveals a significant weight of the implicit component, though: an average of 25\% (12\% in LL, 28.3\% in F2F and 35.7\% in NEF). Such percentages may be taken as proof of important changes in the teaching of grammar, at least as suggested in these textbooks.

Pronunciation is necessarily practised when the speaking skill is activated. However, we refer here only to activities explicitly and exclusively centred on pronunciation as a specific goal. The number of activities devoted to pronunciation is low: it only takes $8.7 \%$ of the total, and $57 \%$ of these are found in one textbook (NEF). Their explicit character is high: it reaches a mean of $85.7 \%$ in the three textbooks, among which the pronunciation activities in F2F are highly explicit (93.8\% of explicitness). 
Interesting differences in the weight of explicitness and implicitness are detected in the vocabulary sections, as shown in Table 33, where data are given so that differences may be more readily perceived and contrasted:

\begin{tabular}{|l|l|l|l|l|l|}
\hline & \multicolumn{3}{|l|}{ Implicitness (\%) } & Explicitness (\%) \\
\hline & & Raw data & Percentage & Raw data & Percentage \\
\hline $\mathbf{N E F}$ & $\begin{array}{l}\text { Vocabulary } \\
\text { Activities }\end{array}$ & 29.9 & 42.8 & 40.1 & 57.2 \\
\hline $\mathbf{F 2 F}$ & $\begin{array}{l}\text { Vocabulary } \\
\text { Activities }\end{array}$ & 82.48 & 63.6 & 37.52 & 36.4 \\
\hline $\mathbf{L L}$ & $\begin{array}{l}\text { Vocabulary } \\
\text { Activities }\end{array}$ & 31.05 & 38.9 & 48.95 & 61.1 \\
\hline
\end{tabular}

Table 3. Implicitness and explicitness in vocabulary activities in the three textbooks

The emphasis on explicit information and awareness becomes evident in NEF and LL (57.2\% and 61.1\%, respectively), while F2F relies more heavily on the implicit character (63.6\%) of the pedagogical action. Regarding implicitness and explicitness, the three textbooks exhibit among each other statistically significant differences $\left(\chi^{2}=20.737, \mathrm{df}=2\right.$, $\mathrm{p}<0.05)$. However, a pair wise contrast shows signs of significance only between NEF vs. F2F $\left(\chi^{2}=11.857, \mathrm{df}=1, \mathrm{p}<0.05\right)$ and F2F vs. LL $\left(\chi^{2}=17.092, \mathrm{df}=1, \mathrm{p}<0.05\right)$, but not between NEF vs. LL $\left(\chi^{2}=0.261, \mathrm{df}=1, \mathrm{p}=0.609\right)$. Clearly, the differences between implicitness and explicitness are particularly marked in F2F, while they turn out to be less prominent between NEF and LL.

\section{CONCLUDING REMARKS}

The process of learning is complex, as is teaching as well. The simple structure underlying the Grammar-translation Method as regards the organization of lessons and the design of activities is far from what we find today in most textbooks. The goals that activities aim at have increased in variety and the strategies put into action are more sophisticated and require more expertise and professional skills from teachers. Succinctly, activities in most textbooks are also complex and cannot be analysed as a one-way pedagogical action.

Activities in the units analysed in this article promote the acquisition of explicit and implicit knowledge. When taken as a whole, the activities (225) under analysis in all three textbooks clearly favour the implicit construct; the features favouring implicitness almost double those that favour explicitness. The distribution of implicitness and explicitness is not equally shared, however, by skill and sub-skill activities and sections. The implicit construct prevails in the skill sections, while explicitness exceeds clearly implicitness in the sub-skill 
activities. Thus, the distribution of the explicit and implicit constructs in the activities adheres to some traditional beliefs. The explicit teaching component is noticeably present throughout the units, although predominantly limited to sections where traditional teaching practices have maintained a leading role (grammar, pronunciation and vocabulary).

According to the data available, one could conclude that implicitness and explicitness are promoted in the teaching units under analysis. The divide between the scholars who claim that explicit teaching extensively contributes to learning and language acquisition and those who advocate implicit teaching as the major or even exclusive component in Foreign Language Teaching will find in our data a point for continuing to argue in one or the other direction. Implicit teaching is not dissociated from more explicit (traditional) practices and convictions.

Still, it must also be acknowledged, following the data presented above, that the teaching process and materials have markedly changed when compared to textbooks in the past. The CLT and its principles clearly underlie the teaching materials offered in the three textbooks given the remarkable presence of activities focused on skill practice. According to our results, recent trends in SLA seem to have been taken into account by textbook writers and materials. We must acknowledge that research in language acquisition and learning has exerted a decisive influence on teaching and teaching materials development. The analysis carried out here deserves more attention, though. The analysis of teaching materials from the perspective of key constructs in SLA may illustrate how and to what extent research SLA insights, on the one hand, and FLT research and practice, on the other, may benefit from one another.

Lastly, we acknowledge a serious limitation in our construct; namely, the difficulty inherent in the elaboration of a construct cemented on highly complex underlying processes. Indeed, it is not an easy task to devise a construct for explicit and implicit teaching which can cover all the different features associated with both types of teaching and which includes them in a way that makes their analysis feasible and measurable. In future research we would like to refine our construct and provide it with further statistical support.

\section{NOTES}

1. This research is financially supported by the Spanish Ministry of Science and Innovation, research project (Ref.: FFI2009-07722), funded by the Plan Nacional de Investigación Científica, Desarrollo e Innovación Tecnológica.

2. Since the graphs have been performed with the Spanish version of Word, a comma appears for decimals instead of a dot in all the figures in each graph. 


\section{REFERENCES}

Anderson, J. R. (1982). Acquisition of cognitive skill. Psychological Review, 89(4), 369-406.

Anderson, J. R., Bothell, D., Byrne, M. D., Douglass, S., Lebiere, C. \& Qin, Y. (2004). An Integrated Theory of the Mind. Psychological Review, 111, 1036-1060.

Anderson, J. R. (2005). Cognitive Psychology and its Implications. New York: Worth Publishers.

Criado Sánchez, R. (2008). Patterns of Activity Sequencing in the Teaching of English as a Foreign Language and their Effects on Learning: A Quasi-experimental Study. PhD Dissertation. University of Murcia, Spain. Retrieved from http://www.tesisenred.net/TDR-1021108094744/index_cs.html

Criado Sánchez, R. (2010). Activity Sequencing in Foreign Language Teaching Textbooks. A Cognitive and Communicative Processes-Based Perspective. Saarbrücken, Germany: LAP Lambert Academic Publishing AG \& Co. KG.

DeKeyser, R.M. (2003). Implicit and explicit learning. In C. J. Doughty \& M. H. Long (Eds.), Handbook of Second Language Acquisition (pp. 313-348). Cambridge, Mass.: Blackwell.

DeKeyser, R.M. (1998). Beyond focus on form: Cognitive perspectives on learning and practicing second language grammar. In C. Doughty \& J. Williams (Eds.), Focus on Form in Classroom Second Language Acquisition (pp. 42-63). Cambridge: Cambridge University Press.

DeKeyser, R. M. (2007a). Skill acquisition theory. In B. VanPatten and J. Williams (Eds.), Theories in Second Language Acquisition. An Introduction (pp. 97-113). Mahwah, N.J.: Lawrence Erlbaum Associates.

DeKeyser, R. M. (2007b). Introduction: Situating the concept of practice. In R. M. DeKeyser (Ed.), Practice in a Second Language. Perspectives from Applied Linguistics and Cognitive Psychology (pp. 1-18). Cambridge: Cambridge University Press.

Dörnyei, Z. (2009). The Psychology of Second Language Acquisition. Oxford: Oxford University Press.

Ellis, N. C. (1994). Implicit and explicit language learning. In N. C. Ellis (Ed.), Implicit and Explicit Learning of Languages (pp. 79-114). San Diego: Academic Press.

Ellis, N. C. (1998). Emergentism, Connectionism and Language Learning. Language Learning, 48(4), 631-664.

Ellis, N. C. (2005). At the interface: Dynamic interactions of explicit and implicit language knowledge. Studies in Second Language Acquisition, 27(2), 305-352.

Ellis, N. C. (2006). Selective attention and transfer phenomena in L2 acquisition: Contingency, cue competition, salience, interference, overshadowing, blocking, and perceptual learning. Applied Linguistics, 27(2), 164-194.

Ellis, N. C. (2007). SLA: The associative-cognitive creed. In B. VanPatten \& J. Williams (Eds.), Theories in Second Language Acquisition: An Introduction (pp. 77-96). Cambridge: Cambridge University Press.

Ellis, R. (1994). A theory of instructed second language acquisition. In N. C. Ellis (Ed.), Implicit and Explicit Learning of Languages (pp. 79-114). London: Academic Press.

Ellis, R. (2005a). Measuring implicit and explicit knowledge of a second language. A psychometric Study. Studies in Second Language Acquisition, 27, 141-172.

Ellis, R. (2005b). Principles of instructed language learning. System, 33, 209-224.

Ellis, R. (2006). Modeling learning difficulty and second language proficiency: The differential contributions of implicit and explicit knowledge. Applied Linguistics, 27(3), 431-463.

Ellis, R. (2007). The differential effects of corrective feedback on two grammatical structures. In A. Mackey (Ed.), Conversational Interaction in Second Language Acquisition: A Collection of Empirical Studies (pp. 339-360). Oxford; New York: Oxford University Press.

Ellis, R. (2009). Implicit and explicit learning, knowledge and instruction. In R. Ellis, S. Loewen, C. Elder, R. Erlam, J. Philp \& H. Reindeers (Eds.), Implicit and Explicit Knowledge in Second Language Learning, Testing and Teaching (pp. 1-26). Bristol: Multilingual Matters.

Hulstijn, J.H. (2003). Incidental and intentional learning. In C. Doughty \& M.H. Long (Eds.), The Handbook of Second Language Research (pp. 349-381). London: Blackwell.

Hulstijn, J. H. (2005). Theoretical and empirical issues in the study of implicit and explicit second language learning: Introduction. Studies in Second Language Acquisition, 27(2), 129-140. 
Johnson, K. (1994). Teaching declarative and procedural knowledge. In M. Bygate, A. Tonkin \& E. Williams (Eds.), Grammar and the Language Teacher (pp. 121-131). London: Prentice Hall.

Johnson, K. (1996). Language Teaching and Skill Learning. Oxford: Blackwell.

Johnson, K. (2008). An Introduction to Foreign Language Learning and Teaching. (2nd ed.). Harlow, Essex, London; New York: Longman.

Krashen, S. (1981). Second language acquisition and second language learning. Oxford, England: Pergamon.

Krashen, S. D. (1982). Principles and Practice in Second Language Learning. London: Pergamon Press Ltd.

Lebeau, I. \& Rees, G. (2008). Language Leader Elementary Coursebook and CD-ROM. Harlow: Pearson/Longman.

Leow, R. P. (1997). Attention, awareness, and foreign language behavior. Language Learning, 47(3), 467-505.

Long, M. \& Robinson, P. (1998). Focus on form: Theory, research and practice. In C. Doughty \& J. Williams (Eds.), Focus on Form in Classroom Second Language Acquisition (pp. 15-41). Cambridge: Cambridge University Press.

Mackey, A. \& Abbuhl, R. (2005). Input and interaction. In C. Sanz (Ed.), Mind \& Context in Adult Second Language Acquisition. Methods, Theory and Practice (pp. 207-233). Washington D. C.: Georgetown University Press.

O’Malley, J. M., Chamot, A. U. \& Walker, C. (1987). Some applications of cognitive theory to second language acquisition. Studies in Second Language Acquisition, 9, 287-306.

Oxenden, C., Latham-Koening, C. \& Seligson, P. (2004). New English File Elementary Student's Book. Oxford: Oxford University Press

Paradis, M. (1994). Neurolinguistic aspects of explicit and implicit memory: implications for bilingualism in SLA. In N. C. Ellis (Ed.), Implicit and explicit learning of languages. (pp. 393418). London: Academic Press.

Paradis, M. (2009). Declarative and Procedural Determinants of Second Languages. Amsterdam: John Benjamins.

Pienemann, M. (1989). Is language teachable? Applied Linguistics, 10, 52-79.

Redston, C. \& Cunningham, G. (2005). Face2face Elementary. Student's Book. Cambridge: Cambridge University Press.

Reinders, H. \& Ellis, R. (2009). The effects of Two Types of Input on Intake and the Acquisition of Implicit and Explicit Knowledge. In R. Ellis, S. Loewen, C. Elder, R. Erlam, J. Philp \& H. Reindeers (Eds.), Implicit and Explicit Knowledge in Second Language Learning, Testing and Teaching (pp. 281-302). Bristol: Multilingual Matters.

Richards J. \& Rodgers, T. (2001). Approaches and methods in language teaching ( ${ }^{\text {nd }}$ ed.) Cambridge: Cambridge University Press.

Robinson, P. (1996). Consciousness, Rules and Instructed Second Language Acquisition. New York: Peter Lang.

Rosa, E. \& O’Neill, M. D. (1999). Explicitness, intake, and the issue of awareness. Studies in Second Language Acquisition, 21(4), 511-556.

Rutherford, W. \& Sharwood Smith, M. (1985). Consciousness raising and universal grammar. Applied Linguistics, 6, 274-82.

Sánchez, A. (2009). La enseñanza de idiomas en los últimos cien años. Métodos y enfoques. Madrid: SGEL, S.A.

Sanz, C. \& Morgan-Short, K. (2005). Explicitness in pedagogical interventions: Input, practice, and feedback. In C. Sanz, (Ed.), Mind \& Context in Adult Second Language Acquisition. Methods, Theory and Practice (pp. 234-263). Washington D.C.: Georgetown University Press.

Sharwood Smith, M. (1991). Speaking to many minds: On the relevance of different types of

language information for the L2 learner. Second Language Research, 7(2), 118-132.

Sharwood Smith, M. (1993). Input enhancement in instructed SLA; theoretical bases. Studies in Second Language Acquisition, 15(2), 165-179.

Schmidt, R. W. (1990). Consciousness in second language learning. Applied Linguistics, 11(2), 129158. 
Schmidt, R. (1993a). Awareness and second language acquisition. Annual Review of Applied Linguistics, 13, 206-226.

Schmidt, R. (1993b). Consciousness, learning, and interlanguage pragmatics. In G. Kasper \& S. BlumKulka (Eds.), Interlanguage pragmatics (pp. 21-42). Oxford: Oxford University Press.

Schmidt, R. (1994). Implicit learning and the cognitive unconscious. In N. C. Ellis (Ed.), Implicit and Explicit Learning of Languages. London: Academic Press.

Schmidt, R. (2001). Attention. In Peter Robinson (Ed.), Cognition and Second Language Instruction (pp. 3-33). New York: Cambridge University Press.

Tomlinson, B. (1998). Introduction. In B. Tomlinson (Ed.), Materials Development in Language Teaching (pp. 1-24). Cambridge: Cambridge University Press.

Wallach, D. \& Lebiere, C. (2003). Implicit and explicit learning in the unified architecture of cognition. In L. Jiménez (Ed.), Attention and Implicit Learning (pp. 215-252). Philadelphia, PA: John Benjamins.

Willis, D. \& Willis, J. (2007). Doing Task-based Teaching. Oxford: Oxford University Press.

\section{APPENDIX. Examples of the overall analysis (section VI)}

1) Oxenden, C., Latham-Koening, C. \& Seligson, P. (2004). New English File Elementary Student's Book. Oxford: Oxford University Press

Unit 7

\begin{tabular}{|l|c|c|c|c|}
\hline \multirow{2}{*}{$\begin{array}{l}\text { Activity no. 33 } \\
\text { 2.a. The presenter from Changing Holidays calls Lisa } \\
\text { Carter. Cover the dialogue. Listen. What are Lisa and } \\
\text { John's plans? }\end{array}$} & \multicolumn{2}{|c|}{ Goals } & \multicolumn{2}{c|}{ Strategies } \\
\cline { 2 - 5 } & Explicit & Implicit & Explicit & Implicit \\
\cline { 2 - 5 } 1. Looks for awareness of formal aspects of the language & & No & Yes & No \\
\hline 2. Focuses on metalinguistic information of the language & & 1 & & 1 \\
\hline 3. Promotes declarative knowledge on the language & & 1 & & 1 \\
\hline 4. Focuses primarily on form & & 1 & & 1 \\
\hline 5. Favours linguistic accuracy & & 1 & & 1 \\
\hline 6. Uses non-authentic materials & & & & 1 \\
\hline 7. Requires the use of L1 & & & & 1 \\
\hline 8. Aims at controlled use of the language & & 1 & & 1 \\
\hline 9. Entails non-meaningful mechanical repetition & & 1 & & 1 \\
\hline & Goals & Strategies & Total & \\
\hline Explicit teaching & 0.0 & 0.00 & 0.00 & \\
\hline Implicit teaching & 10.00 & 10.00 & 10.00 & \\
\hline & & & & \\
\hline
\end{tabular}




\begin{tabular}{|c|c|c|c|c|}
\hline \multirow{3}{*}{$\begin{array}{l}\text { Activity no. } 35 \\
\text { 2.c. Underline the examples of (be) going to in the } \\
\text { dialogue: } \\
\text { 1. What form is the verb going to? } \\
\text { 2. Do we use going to to talk about the past, the present } \\
\text { or the future? }\end{array}$} & \multicolumn{2}{|c|}{ Goals } & \multicolumn{2}{|c|}{ Strategies } \\
\hline & Explicit & Implicit & Explicit & Implicit \\
\hline & Yes & No & Yes & No \\
\hline 1. Looks for awareness of formal aspects of the language & 1 & & 1 & \\
\hline 2. $\quad$ Focuses on metalinguistic information of the language & 1 & & & \\
\hline 3. Promotes declarative knowledge on the language & 1 & & 1 & \\
\hline 4. Focuses primarily on form & 1 & & 1 & \\
\hline 5. $\quad$ Favours linguistic accuracy & 1 & & 1 & \\
\hline 6. Uses non-authentic materials & & & 1 & \\
\hline 7. Requires the use of L1 & & & & 1 \\
\hline 8. $\quad$ Aims at controlled use of the language & 1 & & 1 & \\
\hline \multirow[t]{2}{*}{ 9. Entails non-meaningful mechanical repetition } & & 1 & & 1 \\
\hline & Goals & Strategies & Total & \\
\hline Explicit teaching & 8.57 & 7.50 & 8.04 & \\
\hline Implicit teaching & 1.43 & 2.50 & 1.96 & \\
\hline
\end{tabular}

2) Redston, C. \& Cunningham, G. (2005). Face2face Elementary. Student's Book. Cambridge: Cambridge University Press.

Unit 8

\begin{tabular}{|c|c|c|c|c|}
\hline \multirow{3}{*}{$\begin{array}{l}\text { Activity no. } 2 \\
\text { 2.a. Tick the word/phrases you know. Then do the } \\
\text { exercise in language summary } 8.1 \text { (p 138). }\end{array}$} & \multicolumn{2}{|c|}{ Goals } & \multicolumn{2}{|c|}{ Strategies } \\
\hline & \multirow{2}{*}{$\begin{array}{c}\text { Explicit } \\
\text { Yes }\end{array}$} & \multirow{2}{*}{$\begin{array}{c}\text { Implicit } \\
\text { No }\end{array}$} & \multirow{2}{*}{$\begin{array}{c}\text { Explicit } \\
\text { Yes }\end{array}$} & \multirow{2}{*}{$\begin{array}{c}\text { Implicit } \\
\text { No }\end{array}$} \\
\hline & & & & \\
\hline 1. Looks for awareness of formal aspects of the language & 1 & & 1 & \\
\hline 2. Focuses on metalinguistic information of the language & 1 & & & \\
\hline 3. Promotes declarative knowledge on the language & 1 & & 1 & \\
\hline 4. $\quad$ Focuses primarily on form & 1 & & 1 & \\
\hline 5. Favours linguistic accuracy & 1 & & 1 & \\
\hline 6. Uses non-authentic materials & & & 1 & \\
\hline 7. Requires the use of L1 & & & & 1 \\
\hline 8. Aims at controlled use of the language & 1 & & 1 & \\
\hline \multirow[t]{2}{*}{ 9. Entails non-meaningful mechanical repetition } & & 1 & & 1 \\
\hline & Goals & Strategies & Total & \\
\hline Explicit teaching & 8.57 & 7.50 & 8.04 & \\
\hline Implicit teaching & 1.43 & 2.50 & 1.96 & \\
\hline
\end{tabular}


3) Lebeau, I. \& Rees, G. (2008). Language Leader Elementary Coursebook and CD-ROM. Harlow: Pearson/Longman.

Unit 6

\section{Activity no. 9}

6. Look at the underlined words in the magazine article. Which are countable and which are uncountable?

1. Looks for awareness of formal aspects of the language

2. Focuses on metalinguistic information of the language

3. Promotes declarative knowledge on the language

4. Focuses primarily on form

5. Favours linguistic accuracy

6. Uses non-authentic materials

7. Requires the use of L1

8. Aims at controlled use of the language

9. $\quad$ Entails non-meaningful mechanical repetition

\begin{tabular}{|l|c|c|c|l|}
\hline & 1 & & 1 & \\
\hline Explicit teaching & Goals & Strategies & Total & \\
\hline Implicit teaching & 10.00 & 8.75 & 9.38 & \\
\hline
\end{tabular}

\begin{tabular}{|c|c|c|c|c|}
\hline \multirow{3}{*}{$\begin{array}{l}\text { Activity no. } 131 \text {. } \\
\text { 6.2. Speaking. Read these problems. Are any of them } \\
\text { true for your country? In which countries /regions are } \\
\text { these problems common?. }\end{array}$} & \multicolumn{2}{|c|}{ Goals } & \multicolumn{2}{|c|}{ Strategies } \\
\hline & Explicit & Implicit & Explicit & Implicit \\
\hline & Yes & No & Yes & No \\
\hline 1. Looks for awareness of formal aspects of the language & & 1 & & 1 \\
\hline 2. Focuses on metalinguistic information of the language & & 1 & & \\
\hline 3. Promotes declarative knowledge on the language & & 1 & & 1 \\
\hline 4. Focuses primarily on form & & 1 & & 1 \\
\hline 5. Favours linguistic accuracy & & 1 & & 1 \\
\hline 6. Uses non-authentic materials & & & & 1 \\
\hline 7. $\quad$ Requires the use of L1 & & & & 1 \\
\hline 8. Aims at controlled use of the language & & 1 & & 1 \\
\hline 9. Entails non-meaningful mechanical repetition & & 1 & & 1 \\
\hline & Goals & Strategies & Total & \\
\hline Explicit teaching & 0.00 & 0.00 & 0.00 & \\
\hline Implicit teaching & 10.00 & 10.00 & 10.00 & \\
\hline
\end{tabular}




\begin{tabular}{|l|c|c|c|c|}
\hline \multirow{2}{*}{$\begin{array}{l}\text { Activity no. 34 } \\
\text { 7. Vocabulary. Put the verbs in the right order to make } \\
\text { offers and requests. Then listen and check. Which are } \\
\text { offers and which are requests? }\end{array}$} & \multicolumn{2}{|c|}{ Goals } & \multicolumn{2}{c|}{ Strategies } \\
\cline { 2 - 5 } & Explicit & Implicit & \multirow{2}{*}{ Explicit } & \multirow{2}{*}{ Implicit } \\
\hline 1. Looks for awareness of formal aspects of the language & 1 & & 1 & \\
\hline 2. $\quad$ Focuses on metalinguistic information of the language & 1 & & & \\
\hline 3. $\quad$ Promotes declarative knowledge on the language & 1 & & 1 & \\
\hline 4. $\quad$ Focuses primarily on form & 1 & & 1 & \\
\hline 5. Favours linguistic accuracy & 1 & & 1 & \\
\hline 6. Uses non-authentic materials & & & 1 & \\
\hline 7. Requires the use of L1 & & & & \\
\hline 8. Aims at controlled use of the language & 1 & & 1 & \\
\hline 9. $\quad$ Entails non-meaningful mechanical repetition & 1 & & 1 & \\
\hline & Goals & Strategies & Total & \\
\hline Explicit teaching & 10.00 & 8.75 & 9.38 & \\
\hline Implicit teaching & 0.00 & 1.25 & 0.63 & \\
\hline
\end{tabular}

